\title{
Referral Criteria for Chronic Kidney Disease: Implications for Disease Management and Healthcare Expenditure - Analysis of a Population-Based Sample
}

Simone Kiel ( $\nabla$ simone.kiel@uni-greifswald.de )

University Medicine Greifswald

Gesine Weckmann

European University of Applied Sciences

Jean-François Chenot

University Medicine Greifswald

Sylvia Stracke

KfH Kidney Center Greifswald

Jacob Spallek

Brandenburg University of Technology Cottbus- Senftenberg

Aniela Angelow

University Medicine Greifswald

\section{Research Article}

Keywords: Chronic kidney disease, referral, guideline recommendations, nephrology referral, health care costs

Posted Date: March 3rd, 2022

DOI: https://doi.org/10.21203/rs.3.rs-1365134/v1

License: (c) (1) This work is licensed under a Creative Commons Attribution 4.0 International License. Read Full License 


\section{Abstract}

\section{Background}

Clinical practice guidelines recommend specialist referral according to different criteria. The aim was to assess recommended and observed referral rate and health care expenditure according to recommendations from:

· Kidney Disease Improving Global Outcomes (KDIGO,2012)

- National Institute for Health and Care Excellence (NICE,2014)

- German Society of Nephrology/German Society of Internal Medicine (DGfN/DGIM,2015)

- German Society of General Practitioners and Family Physicians (DEGAM,2019)

- Kidney failure risk equation (NICE,2021)

\section{Methods}

Data of the population-based cohort Study of Health in Pomerania were matched with claims data. Proportion of subjects meeting referral criteria and corresponding health care expenditures were calculated and projected to the population of Mecklenburg-Vorpommern.

\section{Results}

Data from 1927 subjects were analysed. Overall proportion of subjects meeting referral criteria ranged from 4.9\% (DEGAM) to 8.3\% (DGfN/DGIM). The majority of patients eligible for referral were $\geq 60$ years. Estimated population level costs varied between $€ 1,432,440$ (DEGAM) and €2,386,186 (DGfN/DGIM). From 190 patients with eGFR $<60 \mathrm{ml} / \mathrm{min}, 15$ had a risk of end stage renal disease $>5 \%$ within the next 5 years.

\section{Conclusions}

Applying different referral criteria results in different referral rates and costs. Referral rates exceed actually observed consultation rates. Criteria need to be evaluated in terms of available workforce, resources and regarding over- and underutilization of nephrology services.

\section{Introduction}

Chronic kidney disease (CKD) has a prevalence of approximately $9 \%$ in adults worldwide (1). Glomerular filtration rate (GFR) is used to grade kidney function in stages G1-G5. Due to age-dependent decline of kidney function (2), the prevalence of CKD stages 3-5 increases with age and reaches up to $45 \%$ in the age group 75-84 years (3). GFR and proteinuria can be used to grade the severity of CKD and monitor the decline of kidney function (4). The majority of CKD patients are older than 60 years with early stage CKD and are mainly consulting in primary care, where the prevalence is estimated to be nearly $30 \%$ (5). Only a few patients progress to ESRD (end stage renal disease) requiring dialysis $(5,6)$. Referral to specialist care more than one to six months prior to initiation of dialysis was found to reduce mortality and hospitalisation, and improve preparation of dialysis (7).

Internationally, there are numerous clinical practice guidelines and recommendations on management of CKD, with varying referral criteria to specialist nephrology services (8). The Kidney Disease Improving Global Outcomes (KDIGO, 2012), the British guideline from the National Institute of Clinical Excellence (NICE, 2014) guideline and the German College of General Practitioners and Family Physicians (DEGAM, 2019) recommend referral from stage 4 (GFR $<30 \mathrm{ml} / \mathrm{min}$ ) onwards $(4,9,10)$. They also recommend referral with an GFR of 30-59 ml/min and varying additional criteria. The German Societies of Nephrology (DGfN) and Internal Medicine (DGIM) issued a short manual with recommendations in 2015 recommending referral with an eGFR $<45$ $\mathrm{ml} / \mathrm{min}$ (11). In 2021 the NICE guideline was updated and suggested the use of kidney failure risk equation (KFRE) to estimate the 5 -year risk of needing renal replacement therapy (12). A risk of $5 \%$ is suggested as a threshold for referral. 
The aim of referral criteria is to ensure timely and adequate access to nephrology services for patients with most at risk of complications or progression to ESRD and patients requiring specific treatment (13). Avoiding unnecessary referral of low risk patients is usually not an explicitly stated goal, but is important, given the limited number of nephrologists, the high prevalence of CKD and the additional health care expenditures (14). Referral recommendations usually cannot be based on scientific evidence. They rather reflect assumptions or consensus of guideline authors and stakeholders from medical societies.

The aim of this study is to simulate and compare referral rate and corresponding health care expenditure of applying referral criteria according to the following guidelines and recommendations:

- Kidney Disease Improving Global Outcomes (KDIGO, 2012)

- National Institute for Health and Care Excellence (NICE, 2014)

- Recommendation of the German Society of Nephrology/German Society of Internal Medicine (DGfN/DGIM, 2015) and

- German Society of General Practitioners and Family Physicians (DEGAM, 2019).

Additionally we calculated the ESRD risk for subjects with an eGFR $<60 \mathrm{ml} / \mathrm{min}$ using the KFRE as suggested by the update of the NICE guideline 2021, (12).

The second aim is to report the actually observed number of patients consulting a nephrologist.

\section{Methods}

\section{Study design and population}

This is a simulation of applying different referral criteria suggested by various guidelines or recommendations to participants of a population-based cohort study in north-eastern Germany (Study of Health in Pomerania, SHIP). This study provides clinical data of a population sample, independent of actual health service utilization. Data from participants attending the first as well as the second follow-up $(n=2222)$ were included (Fig. 1). Demographic data, somatometry data, standardised laboratory data, selfreported data from a computer assisted interview and data from the medication review were used. Data from the SHIP cohort were individually linked with claims data provided by the Association of Statutory Health Insurance Physicians in MecklenburgVorpommern. Participants with private or no health insurance, participants who did not give informed consent to use claims data and participants with missing laboratory data were excluded from the analysis (Fig. 1). Claims data comprised ICD-10-GM diagnoses (German modification of the 10th revision of the International Classification of Diseases) and billing codes. Written informed consent was obtained from all subjects. The study protocol was approved by the Ethics Committee of the University Medicine Greifswald and can be examined elsewhere (15).

\section{Measurements and data analysis}

Serum creatinine, age and sex were used to calculate estimated Glomerular filtration rate (eGFR) using the CKD-EPI-Eq. (16). A GFR category was assigned to each participant. Albuminuria categories were assigned using the calculated albumin-to-creatinine ratio (ACR). ICD-10-GM-coded diagnoses were used to define morphologic and structural kidney abnormalities (Table 1). Anatomical Therapeutic Chemical Classification System Codes (ATC Codes) were used to classify antihypertensive medication (C02-C09) using data from the medication review. For medication with combined components, the number of components were counted. Referral criteria were defined according to guideline recommendations using laboratory and blood pressure values (calculated as the mean of the 2nd and 3rd blood pressure measurement, systolic $>150$ and/or diastolic $>90 \mathrm{mmHg}$ ), medication and billing codes (Table 1). Based on these criteria, we assigned a referral recommendation to each participant and estimated the proportion of participants eligible for referral according to each investigated guideline/recommendation. Additionally, billing codes were used to see who was actually referred and consulted a nephrologist within 1 year and 3 years prior to study examination (SHIP-2). 
Table 1

Overview of criteria for referral recommendations

\begin{tabular}{|c|c|c|c|c|c|}
\hline \multirow[t]{2}{*}{ Guideline definition } & \multirow[t]{2}{*}{ Study data definition } & \multicolumn{4}{|c|}{ Referral criteria } \\
\hline & & DEGAM & DGfN/DGIM & $\begin{array}{l}\text { NICE } \\
2014\end{array}$ & KDIGO \\
\hline \multicolumn{6}{|l|}{ Kidney function } \\
\hline GFR & eGFR (ml/min) & $\begin{array}{l}<30 \text { or } \\
30-59 \\
2 \text { and }\end{array}$ & $\begin{array}{l}<45 \text { or } 45- \\
59 \text { and }\end{array}$ & $\begin{array}{l}<30 \\
\text { or } \\
30- \\
59 \\
\text { and }\end{array}$ & $\begin{array}{l}<30 \text { or } \\
30-59 \\
\text { and }\end{array}$ \\
\hline $\begin{array}{l}\text { GFR progression > } 5 \\
\mathrm{ml} / \mathrm{min} / \text { year }\end{array}$ & $\begin{array}{l}\text { mean eGFR reduction }>5 \mathrm{ml} / \mathrm{min} \text { from first to second } \\
\text { follow-up examination }\end{array}$ & & $\mathrm{x}$ & & \\
\hline $\begin{array}{l}\text { GFR progression }>5 \\
\mathrm{ml} / \mathrm{min} / \text { year or }\end{array}$ & $\begin{array}{l}\text { mean eGFR reduction }>5 \mathrm{ml} / \mathrm{min} \text { from first to second } \\
\text { follow-up examination or mean eGFR reduction of } \geq \\
25 \%\end{array}$ & & & & $x$ \\
\hline \multicolumn{6}{|l|}{$\begin{array}{l}\text { GFR reduction } \geq \\
25 \% \text { / year }\end{array}$} \\
\hline $\begin{array}{l}\text { GFR progression } \geq \\
15 \mathrm{ml} / \mathrm{min} / \text { year or }\end{array}$ & $\begin{array}{l}\text { mean eGFR reduction }>15 \mathrm{ml} / \mathrm{min} \text { from first to second } \\
\text { follow-up examination or mean eGFR reduction of } \geq \\
25 \%\end{array}$ & & & $\mathrm{x}$ & \\
\hline \multicolumn{6}{|l|}{$\begin{array}{l}\text { GFR reduction } \geq \\
25 \% \text { / year }\end{array}$} \\
\hline \multicolumn{6}{|l|}{$\begin{array}{l}\text { Hypertension } \\
\text { refractory to } \\
\text { treatment }\end{array}$} \\
\hline $\begin{array}{l}\mathrm{BP}>150 \text { and/or }> \\
90 \mathrm{mmHg} \text { and }\end{array}$ & BP: mean systolic BP of 2. and 3. measurement & $\mathrm{x}$ & $\mathrm{x}$ & & \\
\hline $\begin{array}{l}\geq 3 \\
\text { antihypertensives }\end{array}$ & Antihypertensives : ATC-codes C02-C09 & & & & \\
\hline $\begin{array}{l}\mathrm{BP}>150 \text { and/or }> \\
90 \mathrm{mmHg} \text { and }\end{array}$ & BP: mean systolic BP of 2. and 3. measurement & & & $\mathrm{x}$ & $\mathrm{x}$ \\
\hline $\begin{array}{l}\geq 4 \\
\text { antihypertensives }\end{array}$ & Antihypertensives : ATC-codes C02-C09 & & & & \\
\hline \multicolumn{6}{|l|}{ Proteinuria } \\
\hline $\begin{array}{l}\text { Proteinuria > } 200 \\
\mathrm{mg} / \mathrm{l}\end{array}$ & $\begin{array}{l}\text { Urine albumin dipstick category, subjects with diabetes: } \\
\text { urine protein dipstick category }\end{array}$ & & $\mathrm{x}$ & & \\
\hline \multicolumn{6}{|l|}{$\begin{array}{l}\text { subjects with } \\
\text { diabetes: }>20 \mathrm{mg} / \mathrm{l}\end{array}$} \\
\hline $\begin{array}{l}\text { Albuminuria } \geq 300 \\
\mathrm{mg} / \mathrm{g} \text { or } \geq 30 \\
\mathrm{mg} / \mathrm{mmol}\end{array}$ & ACR & & & & $\mathrm{x}$ \\
\hline
\end{tabular}

ACR: Albumin-Creatinin-Ratio, ATC: Anatomical Therapeutic Chemical (ATC) Classification System Code, BP: Blood Pressure, eGFR: estimated Glomerular Filtration Rate, ICD-10-GM: DEGAM: German society of general practice and family medicine, DGIM, German society of internal medicine, DGfN: German society of Nephrology, German modification of the 10th revision of the International Classification of Diseases; NICE: National Institute of Health and Care Excellence, KDIGO: Kidney Disease Improving Global Outcomes, WHO: World Health Organisation

${ }^{1}$ KDIGO criterium "erythrocyte cylinder or erythrocytes in spot urine > 20/high power field" was defined by substituting $1 \mu$ for one high power field, which correlates to a $2++$ urinary dip stick score in SHIP data

${ }^{2}$ DEGAM made a good clinical practice point that younger patients with a low eGFR should be referred liberally, while in older patients ( $>70$ years old) with eGFR $<30 \mathrm{ml} / \mathrm{min}$ comorbidity, life expectancy and individual patient goals should be considered. 


\begin{tabular}{|c|c|c|c|c|c|}
\hline \multirow[t]{2}{*}{ Guideline definition } & \multirow[t]{2}{*}{ Study data definition } & \multicolumn{4}{|c|}{ Referral criteria } \\
\hline & & DEGAM & DGfN/DGIM & $\begin{array}{l}\text { NICE } \\
2014\end{array}$ & KDIGO \\
\hline $\begin{array}{l}\text { Proteinuria } \geq 70 \\
\mathrm{mg} / \mathrm{mmol} \text { and } \\
\text { non-diabetic }\end{array}$ & ACR & & & $x$ & \\
\hline $\begin{array}{l}\text { Albuminuria } \geq 30 \\
\mathrm{mg} / \mathrm{g} \text { or } \\
\geq 3 \mathrm{mg} / \mathrm{mmol}\end{array}$ & ACR & $x$ & & & \\
\hline $\begin{array}{l}\mathrm{ACR} \geq 30 \mathrm{mg} / \mathrm{mmol} \\
\text { and haematuria }\end{array}$ & ACR and urine dipstick category red blood cells ++ & & & $x$ & \\
\hline \multicolumn{6}{|l|}{ Haematuria } \\
\hline $\begin{array}{l}\text { Micro- or } \\
\text { macrohematuria }\end{array}$ & urine dipstick category red blood cells ++1 & & $x$ & & $\mathrm{x}$ \\
\hline $\begin{array}{l}\text { Haematuria without } \\
\text { known urologic } \\
\text { cause }\end{array}$ & urine dipstick category red blood cells ++1 & $x$ & & & \\
\hline \multicolumn{6}{|c|}{ Morphologic and structural kidney abnormalities } \\
\hline \multirow{3}{*}{$\begin{array}{l}\text { Morphologic kidney } \\
\text { changes }\end{array}$} & ICD-10-GM codes & & $x$ & & \\
\hline & $\begin{array}{l}\text { - at least one billing code one year prior to study } \\
\text { examination of second follow-up (N02.-, N20.-) }\end{array}$ & & & & \\
\hline & $\begin{array}{l}\text { - at least one billing code five years prior to study } \\
\text { examination of second follow-up (N11.-, N13.-, N26.-, } \\
\text { N28.-, C64.-, D41.0, Q61.-, Q63.-, I70.1) }\end{array}$ & & & & \\
\hline Kidney stones & $\begin{array}{l}\text { ICD-10-GM codes N20.-, at least one billing code one } \\
\text { year prior to study examination of second follow-up }\end{array}$ & & & & $\mathrm{x}$ \\
\hline $\begin{array}{l}\text { Renal artery } \\
\text { stenosis }\end{array}$ & $\begin{array}{l}\text { ICD-10-GM code I70.1, at least one billing code five years } \\
\text { prior to study examination of second follow-up }\end{array}$ & & & $x$ & \\
\hline \multicolumn{6}{|l|}{ miscellaneous } \\
\hline Hypocalcaemia & $<2.12 \mathrm{mmol} / \mathrm{l}$ & & $x$ & & \\
\hline Hyperphosphatemia & $>1.6 \mathrm{mmol} / \mathrm{l}$ & & $x$ & & \\
\hline $\begin{array}{l}\text { Abnormalities of } \\
\text { serum potassium }\end{array}$ & Serum potassium $<3.7 \mathrm{mmol} / \mathrm{l}$ or $>5.1 \mathrm{mmol} / \mathrm{l}$ & & & & $x$ \\
\hline $\begin{array}{l}\text { Inherited kidney } \\
\text { disease }\end{array}$ & $\begin{array}{l}\text { ICD-10-GM codes, at least one billing code five years } \\
\text { prior to study examination of second follow-up (Q61.-, } \\
\text { Q63.-) }\end{array}$ & & & $x$ & $x$ \\
\hline
\end{tabular}

ACR: Albumin-Creatinin-Ratio, ATC: Anatomical Therapeutic Chemical (ATC) Classification System Code, BP: Blood Pressure, eGFR: estimated Glomerular Filtration Rate, ICD-10-GM: DEGAM: German society of general practice and family medicine, DGIM, German society of internal medicine, DGfN: German society of Nephrology, German modification of the 10th revision of the International Classification of Diseases; NICE: National Institute of Health and Care Excellence, KDIGO: Kidney Disease Improving Global Outcomes, WHO: World Health Organisation

${ }^{1}$ KDIGO criterium "erythrocyte cylinder or erythrocytes in spot urine $>20 /$ high power field" was defined by substituting $1 \mu$ f for one high power field, which correlates to a $2++$ urinary dip stick score in SHIP data

${ }^{2}$ DEGAM made a good clinical practice point that younger patients with a low eGFR should be referred liberally, while in older patients ( $>70$ years old) with eGFR $<30 \mathrm{ml} / \mathrm{min}$ comorbidity, life expectancy and individual patient goals should be considered. 


\begin{tabular}{|c|c|c|c|c|c|}
\hline \multirow[t]{2}{*}{ Guideline definition } & \multirow[t]{2}{*}{ Study data definition } & \multicolumn{4}{|c|}{ Referral criteria } \\
\hline & & DEGAM & DGfN/DGIM & $\begin{array}{l}\text { NICE } \\
2014\end{array}$ & KDIGO \\
\hline Anaemia & $\begin{array}{l}\text { WHO reference values haemoglobin, female: }<7.4 \\
\mathrm{mmol} / \mathrm{l} \text {, male: }<8.1 \mathrm{mmol} / \mathrm{l}\end{array}$ & & $x$ & & \\
\hline \multicolumn{6}{|c|}{$\begin{array}{l}\text { ACR: Albumin-Creatinin-Ratio, ATC: Anatomical Therapeutic Chemical (ATC) Classification System Code, BP: Blood Pressure, } \\
\text { eGFR: estimated Glomerular Filtration Rate, ICD-10-GM: DEGAM: German society of general practice and family medicine, } \\
\text { DGIM, German society of internal medicine, DGfN: German society of Nephrology, German modification of the } 10 \text { th revision of } \\
\text { the International Classification of Diseases; NICE: National Institute of Health and Care Excellence, KDIGO: Kidney Disease } \\
\text { Improving Global Outcomes, WHO: World Health Organisation }\end{array}$} \\
\hline \multicolumn{6}{|c|}{$\begin{array}{l}{ }^{1} \text { KDIGO criterium "erythrocyte cylinder or erythrocytes in spot urine }>20 / \text { high power field" was defined by substituting } 1 \mu \text { for } \\
\text { one high power field, which correlates to a } 2++ \text { urinary dip stick Score in SHIP data }\end{array}$} \\
\hline \multicolumn{6}{|c|}{$\begin{array}{l}2 \text { DEGAM made a good clinical practice point that younger patients with a low eGFR should be referred liberally, while in older } \\
\text { patients ( }>70 \text { years old) with eGFR }<30 \mathrm{ml} / \mathrm{min} \text { comorbidity, life expectancy and individual patient goals should be } \\
\text { considered. }\end{array}$} \\
\hline
\end{tabular}

In a second step, referral recommendations and age were used to estimate costs associated with nephrologist consultation. Costs were assigned based on billing codes and the official doctor's fee scale of the National Association of Statutory Health Insurance Physicians from 2019 (billing codes 13591 base fee schedule $€ 26.62$ for patients aged 6 to 59 years and 13592 base fee schedule $€ 27.60$ for patients aged $\geq 60$ years).

To estimate population level referral rates based on the SHIP cohort, the proportion of persons eligible for referral in the age categories 30 to 59 years and 60 to 90 years was multiplied with the number of persons in the same age categories according to the statistical office Mecklenburg-Vorpommern 2017 (17). For pragmatic reasons, we assume that each patient is referred only once. Population level costs were estimated for each age category using costs as defined above. Descriptive analyses were performed using SAS Institute Inc., Cary, NC, USA, Software 9.4. This study has been reported in accordance with STROBE guidelines (Supplementary Table S2).

\section{Results}

\section{Patient characteristics}

A total of 1927 subjects $\left(53 \%(1030 / 1927)\right.$ female; median age $\left.=59, Q_{1}: 48 ; Q_{3}: 69\right)$ were included in the analysis (Fig. 1). Of those, $2.8 \%$ (53/1927) had an eGFR < 45ml/min (GFR category 3b, 4 or 5) and 7,1\% (137/1927) an eGFR between $45-59 \mathrm{ml} / \mathrm{min}$ (GFR category 3a) (Table 2). A blood pressure $>150 \mathrm{mmHg}$ systolic and/or $>90 \mathrm{mmHg}$ diastolic was measured in $24 \%$ (468/1927). 
Table 2

Characteristics of the study population, $\mathrm{N}=1927$

\begin{tabular}{|c|c|c|c|c|c|}
\hline Characteristic & $\begin{array}{l}\text { GFR category G1, G2 (60-89; } \\
\geq 90 \mathrm{ml} / \mathrm{min})\end{array}$ & $\begin{array}{l}\text { GFR } \\
\text { category } \\
\text { G3a } \\
\text { (45-59 } \\
\mathrm{ml} / \mathrm{min})\end{array}$ & $\begin{array}{l}\text { GFR } \\
\text { category } \\
\text { G3b } \\
\text { (30-44 } \\
\mathrm{ml} / \mathrm{min})\end{array}$ & $\begin{array}{l}\text { GFR } \\
\text { category } \\
\text { G4 } \\
(15-29 \\
\mathrm{ml} / \mathrm{min})\end{array}$ & $\begin{array}{l}\text { GFR } \\
\text { category } \\
\text { G5 } \\
\text { (<15 } \\
\mathrm{ml} / \mathrm{min} \text { ) }\end{array}$ \\
\hline & $n=1737$ & $n=137$ & $\mathrm{n}=42$ & $n=9$ & $\mathrm{n}=2$ \\
\hline & $(90.1 \%)$ & $(7.1 \%)$ & $(2.2 \%)$ & $(0.5 \%)$ & $(0.1 \%)$ \\
\hline Female n (\%) & $930(53.5)$ & $76(55.5)$ & $20(47.6)$ & $3(33.3)$ & $1(50)$ \\
\hline Age, mean $( \pm S D)$ (years) & $56.7(12.9)$ & $73(6.7)$ & $77.5(8.2)$ & $80(8.7)$ & $65(14.1)$ \\
\hline Range (years) & $31-89$ & $56-93$ & $57-90$ & $66-89$ & $55-75$ \\
\hline $\begin{array}{l}\text { Hypertension > } 150 \text { and/or > } \\
90 \text { mmHg, } \\
\mathrm{n}(\%)\end{array}$ & $401(23.1)$ & $49(35.8)$ & $14(33.3)$ & $3(33.3)$ & $1(50)$ \\
\hline $\begin{array}{l}\text { Diabetes (self-reported), } \mathrm{n} \\
(\%)\end{array}$ & $194(11.2)$ & $37(27)$ & $16(38.1)$ & $6(66.7)$ & $1(50)$ \\
\hline $\begin{array}{l}\text { Albuminuria } \geq 300 \mathrm{mg} / \mathrm{g} \text { or } \\
\geq 30 \mathrm{mg} / \mathrm{mmol}, \mathrm{n}(\%)\end{array}$ & $25(1.4)$ & $6(4.4)$ & $7(16.7)$ & $2(22.2)$ & $1(50)$ \\
\hline Anaemia, n (\%) & $104(6)$ & $21(15.3)$ & $15(35.7)$ & $3(33.3)$ & $1(50)$ \\
\hline $\begin{array}{l}\text { Abnormalities of serum } \\
\text { potassium, } \mathrm{n}(\%)\end{array}$ & $84(4.8)$ & $15(11)$ & $9(21.4)$ & $1(11.1)$ & $1(50)$ \\
\hline Hypocalcaemia, n (\%) & $71(4)$ & $3(2.2)$ & $4(9.5)$ & $0(0)$ & $0(0)$ \\
\hline $\begin{array}{l}\text { Morphologic kidney changes, } \\
\text { n (\%) }\end{array}$ & $270(15.5)$ & $49(35.7)$ & $16(38.1)$ & $2(22.2)$ & $1(50)$ \\
\hline Kidney stones, n (\%) & $100(5.8)$ & $16(11.7)$ & $1(2.4)$ & $0(0)$ & $0(0)$ \\
\hline $\begin{array}{l}\text { Inherited kidney disease, } \mathrm{n} \\
(\%)\end{array}$ & $120(6.9)$ & 24 (17.5) & $6(14.3)$ & $0(0)$ & $0(0)$ \\
\hline Haematuria, n (\%) & $97(5.6)$ & $10(7.3)$ & $3(7.1)$ & $2(22.2)$ & $0(0)$ \\
\hline
\end{tabular}

Diabetes was self-reported by $13.2 \%$ (254/1927). Kidney stones were diagnosed in $6.1 \%(117 / 1927)$ and morphologic kidney changes in $17.5 \%(338 / 1927)$. The proportion of subjects with hypertension or diabetes was higher among subjects with reduced eGFR (Table 2).

\section{Participants eligible for referral}

The overall proportion of participants eligible for referral to specialist nephrologist ranged from $4.9 \%$ according to DEGAM criteria to $8.3 \%$ according to the DGfN/DGIM criteria (Table 3). According to all guidelines/recommendations, the majority of patients eligible for referral were 60 years or older (>95\%, Table S1). In participants aged 60 years or older, DGfN/DGIM criteria yielded the highest proportion eligible for referral (16.5\%) and DEGAM criteria the lowest (9.7\%). Overall, estimated yearly cost based on a single referral to specialist nephrologist was between $€ 2,618$ and $€ 4,384$ (Table 3). 
Table 3

Estimated referral rates according to different guidelines and the corresponding costs, $N=1927$

\begin{tabular}{|c|c|c|c|c|}
\hline \multirow{2}{*}{$\begin{array}{l}\text { Guideline } \\
\text { (year) }\end{array}$} & \multirow[t]{2}{*}{$\begin{array}{l}\text { Participants eligible for } \\
\text { referral n, (\%) }\end{array}$} & \multicolumn{2}{|c|}{$\begin{array}{l}\text { Participants eligible for referral by } \\
\text { age category, } n(\%)\end{array}$} & \multirow[t]{2}{*}{$\begin{array}{l}\text { estimated referral costs }(€)^{3} \text { according } \\
\text { to referral criteria }\end{array}$} \\
\hline & & $<60$ years $^{1}$ & $\geq 60$ years $^{2}$ & \\
\hline $\begin{array}{l}\text { DGfN/DGIM } \\
(2015)\end{array}$ & 159/1927 (8.3) & $4(0.4)$ & $155(16.5)$ & $4,384.48$ \\
\hline $\begin{array}{l}\text { KDIGO } \\
(2012)\end{array}$ & 148/1927 (7.7) & $4(0.4)$ & $144(15.3)$ & $4,080.88$ \\
\hline NICE (2014) & $103 / 1927(5.4)$ & $3(0.3)$ & $100(10.6)$ & $2,839.86$ \\
\hline $\begin{array}{l}\text { DEGAM } \\
(2019)\end{array}$ & 95/1927 (4.9) & $4(0.4)$ & $91(9.7)$ & $2,618.08$ \\
\hline \multicolumn{5}{|c|}{$\begin{array}{l}1 \text { proportions based on } n=987 \text { participants aged }<60 \text { years, }{ }^{2} \text { proportions based on } n=940 \text { participants aged } \geq 60 \text { years. } \\
\text { Estimates based on a single specialist nephrologist consultation per person, excluding laboratory tests and ultrasound and } \\
\text { biopsy, } € 26.62 / \text { consultation for patients }<60 \text { years, } € 27.60 / \text { consultation for patients } \geq 60 \text { years }\end{array}$} \\
\hline \multicolumn{5}{|c|}{$\begin{array}{l}\text { DGfN/DGIM: German Society of Nephrology/German Society of Internal Medicine; KDIGO: Kidney Disease Improving Global } \\
\text { Outcomes; NICE: National Institute for Health and Care Excellence; DEGAM: German Society of General Practitioners and } \\
\text { Family Physicians }\end{array}$} \\
\hline
\end{tabular}

\section{Patients actually consulting a nephrologist}

A total of 55/1927 (2.9\%) subjects actually consulted a nephrologist (GOP 13591, GOP 13592) within 1 year prior to study examination (SHIP-2). Of those, 33 participants consulted only once, 13 participants twice, 6 participants 3 times and 3 participants 4 times within 1 year. Within 3 years prior to study examination, 75/1927 (3.9\%) subjects consulted a nephrologist. Of those consulting a nephrologist within 1 year prior to study examination $(n=55), 12$ patients fulfilled referral criteria according to DGfN/DGIM and KDIGO, 9 patients according to NICE criteria and 10 patients according to DEGAM criteria (Fig. 2). Participants eligible for referral according to the DGfN/DGIM criteria were older (median age 75 years) and had a lower eGFR (median 50 $\mathrm{ml} / \mathrm{min}$ ) than those who were actually referred and consulted a nephrologist (median age 57 years, median eGFR $91 \mathrm{ml} / \mathrm{min}$ ). Of the 190 participants with an eGFR $<60 \mathrm{ml} / \mathrm{min}$ a total of $15 \mathrm{had}$ a risk $>5 \%$ for ESRD according to KFRE, but only 3 , mostly younger patients ( $<60$ years old) had a nephrology consultation. The average age of the non-referred patients was 78 years (range 58-90).

\section{Estimated population level referral and corresponding costs for Mecklenburg-Vorpommern}

There were 675,871 persons aged 30-59 and 508,177 persons aged 60-90 living in the state Mecklenburg-Vorpommern in the year 2017 (17). Based on the referral rates according to different guidelines (Table 3), estimated population level total cost for nephrologist referral amounted to $€ 1,432,440$ (DEGAM) and reached up to $€ 2,386,186$ (KDIGO) (Table 4). 
Table 4

Estimated population level referral rates for Mecklenburg-Vorpommern, Germany and the corresponding cost

\begin{tabular}{|c|c|c|c|c|c|}
\hline \multirow[t]{2}{*}{$\begin{array}{l}\text { Guideline } \\
\text { (year) }\end{array}$} & \multicolumn{2}{|c|}{$\begin{array}{l}\text { Eligible for referral by age category } \\
\mathrm{n}(\%)\end{array}$} & \multicolumn{2}{|c|}{ Referral cost $\left(€^{1}\right)$} & \multirow[t]{2}{*}{ Total cost $\left(€^{1}\right)$} \\
\hline & Aged $<60$ & Aged $\geq 60$ & Aged $<60$ & Aged $\geq 60$ & \\
\hline DGfN/DGIM (2015) & $2,703(0.4)$ & $83,849(16.5)$ & $71,953.86$ & $2,314,232.40$ & $2,386,186.26$ \\
\hline KDIGO (2012) & $2,703(0.4)$ & $77,751(15.3)$ & $71,953.86$ & $2,145,927.60$ & $2,217,881.46$ \\
\hline NICE (2014) & $2,027(0.3)$ & $53,866(10.6)$ & $53,958.74$ & $1,486,701.60$ & $1,540,660.34$ \\
\hline DEGAM (2019) & $2,703(0.4)$ & 49,293 (9.7) & $71,953.86$ & $1,360,486.80$ & $1,432,440.66$ \\
\hline
\end{tabular}

${ }^{1}$ Estimates based on 675,871 people $<60$ years old; $508,177 \geq 60$ years old, and a single specialist nephrologist consultation per person, excluding laboratory tests and imaging; $€ 26.62 /$ consultation for patients $<60$ years, $€ 27.60 /$ consultation for patients $\geq 60$ years

DGfN/DGIM: German Society of Nephrology/German Society of Internal Medicine; KDIGO: Kidney Disease Improving Global Outcomes; NICE: National Institute for Health and Care Excellence; DEGAM: German Society of General Practitioners and Family Physicians

\section{Discussion}

\section{Summary of the main results}

The aim of our analysis was to estimate and compare actual consultation rate and recommended referral rates to specialist nephrology services as well as corresponding costs, based on different guideline recommendations. The proportion of subjects meeting referral criteria and associated cost differed between guidelines. DEGAM criteria yielded an overall referral rate of $4.9 \%$, while applying DGfN/DGIM criteria resulted in a referral rate of $8.3 \%$. In subjects older than 60 years, differences were even more pronounced, and rates ranged from 9.7\% (DEGAM) to 16.5\% (DGFN/DGIM). The observed actual nephrology consultation rate (2.9\%) was lower and there was mismatch between eligible and referred subjects (Fig. 2). The estimated population level total costs for implementing referral criteria in the state Mecklenburg-Vorpommern, Germany, varied between $€ 1,432,440$ (DEGAM) and $€ 2,386,186$ (DGfN/DGIM) based upon a population of almost 1.2 million, but only considering a single specialist nephrology consultation.

\section{Meaning of the results and comparison with literature}

CKD is one of the fastest growing chronic diseases due to demographic changes (1)[1,3]. Moreover, the prevalence of obesity, diabetes and hypertension is increasing worldwide, which will potentially increase CKD prevalence even further (1). Since age related decline in GFR is assumed to be an important driver of the increase in prevalence, a call for an age-adapted definition of CKD has been made (18). This aspect has been taken into consideration by the DEGAM guideline which made a good clinical practice point for individual assessment of the benefits of nephrology referrals in older patients. However, the available data did not allow to make such judgements. We assume we overestimate the number of patients for whom a referral would be of clinical benefit. This might also explain the lower proportion of observed actual nephrology consultations.

Measurements of albumin-to-creatinine ratio (ACR) were not performed in ambulatory care according to the available billing data. In our sample we identified subjects with proteinuria according to ACR measurement within the frame of the cohort study. We can therefore assume that the degree or proteinuria was unknown to the treating physicians. This explains on the one hand the higher proportion of referrals according to recommendations and on the other hand the mismatch between consulting and referred patients.

In Germany, the prevalence of CKD in the adult population under 80 years is estimated to range between $2.3 \%$ based on GFR and $11.5 \%$ based on proteinuria, resulting in more than 10 million of the general population and more than $50 \%$ of nursing home residents meeting the criteria for $\operatorname{CKD}(6,19)$. Due to the high prevalence of CKD in combination with ultimately limited resources 
in the healthcare system in terms of specialist care services and cost, referral criteria for CKD have important implications for health care resource allocation (14).

Late referral to specialist nephrology services has been reported and associated with worse outcomes (20). It has to be considered that a relevant proportion of ESRD is not preventable or cannot be optimally prepared for renal replacement therapy with preventive nephrologic services. This is on the one hand due to rapid and unpredictable decline in renal function or acute health conditions $(21,22)$. On the other hand, progression to ESRD occurs in some patients despite best therapeutic efforts. It is assumed, that early referral defined as 6 or 12 months prior to renal replacement therapy or referral at GFR $<60 \mathrm{ml} / \mathrm{min}$ (CKD stage 3a) could potentially contribute to delay progression and improve prognosis in patients with CKD $(7,23)$. These assumptions were based on retrospective data of patients with end stage renal disease and dialysis, where early referral was found to be associated with better preparation and placement of dialysis access, while improved care was defined according to frequency of blood pressure measurements and management of diabetes (23). Although these are important factors in CKD management, retrospective analyses of this kind based on the small fraction of CKD patients who will reach ESRD, cannot be used to draw conclusions about the wider population of predominantly older patients with stable CKD (24). In fact, the challenge is to distinguish between the large number of CKD patients with stable or slowly declining kidney function and low lifetime ESRD risk and patients who require specialist care because of likely progression to ESRD or treatment of uremic complications such as CKD-MBD, renal anaemia or metabolic acidosis.

Since the majority of studies regarding CKD have been conducted in clinical settings and with high risk patients, formulating referral criteria for primary care and other low risk settings is challenging (13). Recent guidelines have tried to formulate referral criteria aimed at distinguishing between patients with low versus high risk for ESRD (4, 8-11). Analyses of estimated implications of KDIGO referral criteria for the US indicate, that referral criteria do not effectively distinguish between high and low risk patients, when applied to primary care or population based cohorts (25). It was estimated, that implementing KDIGO referral criteria in a primary care population would result in a $38 \%$ increase in total nephrology patient volume and a $67 \%$ increase in new referrals, leading to a supply-demand mismatch of available workforce and resources (25). This is in line with the results of our analysis, where implementing KDIGO criteria would lead to more than double increase in referral rate compared to actual referral $(7.7 \%$ vs. $3 \%)$.

KDIGO, DGfN/DGIM and NICE (2014) criteria aim to identify high risk subgroups by proposing additional criteria for CKD patients with reduced GFR, including haematuria, albuminuria and refractory hypertension. The differences between the referral rates of the different criteria are small. We assume that criteria do not succeed in distinguishing high-risk subgroups in older patients, resulting in excessive referral rates of 16.5\% (DGFN/DGIM) and 10.6\% (NICE 2014) in persons aged $\geq 60$ years. Implementing DEGAM criteria, resulted in the lowest overall referral rate of $5 \%$ at the population level, but even the strict application of these criteria resulted in a $9.7 \%$ referral rate in patients aged $\geq 60$ years. This has implications if referral criteria are used for quality measurements. In our analysis, only a minority of participants referred, fulfilled the stipulated referral criteria (Fig. 2). The participants actually referred had a higher eGFR and were younger than those who were not referred but were eligible for referral. Our results show that the DGFN/DGIM criteria are not used in clinical practice.

Although our data set exceeds data usually available, in which ACR is often not included, the data do not allow to fully assess the appropriateness of selection of patients who are most likely to benefit from specific nephrology services. The KFRE identified the lowest proportion of participants eligible for nephrology referral, but only 3 out of $15(20 \%)$ actually received a referral. This should be interpreted cautiously since other relevant comorbidities or individual arrangements cannot be excluded. It is conceivable that the risk of ESRD was underestimated in some participants, where treating physicians were not aware of the amount of proteinuria. One should keep in mind that NICE 2021 suggests additionally other criteria like decrease eGFR $>25 \%$ in 12 months, suspected genetic disease and suspected renal artery stenosis (12).

Ambulatory physicians should measure ACR more frequently to make referral decisions. This has implications for monitoring quality of medical services based on current referral recommendations.

There are limited treatment options for improving CKD prognosis (26), apart from hypertension and diabetes management, which are recommended regardless of kidney function, and despite recent progress with Sodium-Glucose Cotransporter-2 (SGLT2)

Page 10/15 
Inhibitors. Therefore, there is no rationale for mandatory early referral of patients with uncomplicated or early CKD stages or with stable GFR considering patients age. Management of these patients can be provided by general practitioners and clinical practice guidelines on blood pressure and diabetes management are available. This approach would yield a potential cost reduction while preserving quality of care and should be complemented by conservative referral criteria, accounting for age, comorbidity and risk of ESRD. At the same time, general practitioners describe a need for informal shortcuts for specialist advice when faced with older, multimorbid patients with conflicting health care needs and low lifetime risk of ESRD $(22,27)$.

\section{Recommendations for research and future guideline development}

Due to the strong association of kidney function with age (age dependent decline), there is a need of an age-dependent approach to management and referral, incorporating CKD prognosis and comorbidities. Proposed age-adjusted CKD criteria were postulated by Delanaye et al. (2019), based on a meta-analysis of mortality risk in different eGFR stages (18). Applying these criteria might be an additional factor in identifying patients with high ESRD risk from those with age related kidney function decline. Prospective population based analyses on the natural history of CKD, mortality and clinically relevant endpoints in a low-risk or primary care setting are scarce (28). Recently, the Kidney Failure Risk Equation (KFRE) for predicting the 2 and 5 year probability of ESRD was successfully validated in a British primary care setting and a large Canadian study population (28-30). Based on this equation, tools to recommend referral to a nephrologist were developed and could be used to optimise referral recommendations (31). This has already led to a change in the updated NICE Guideline 2021 which recommends the use of the KFRE instead of an eGFR on its own for referral recommendation (12). Further research, ideally based on large, prospective, primary care-based cohorts, would be needed to further validate evidence-based referral criteria and existing prediction tools. Future guidelines should consider ESRD in referral recommendations. Research has shown, that treatment burden is significant in patients with CKD. Future research should address the role of specialist referral on burden of disease and quality of life in CKD patients in the German healthcare setting (32, 33).

\section{Strengths and Limitations}

This is the first study to our knowledge simulating the implications of applying different referral criteria for CKD in a German population. Our analysis is based on population-based data, which allowed to consider ACR, which is not routinely measured. However, it is limited due to the attrition bias (loss-to-follow up). We might underestimate the number of referred patients, since we cannot exclude that some patients received a referral but did not actually consult. We assume that true costs are much higher than calculated, because billing codes did not reflect all cost associated with referral (laboratory tests, ultrasound) and in reality, multiple follow up visits are common. Since this limitation affects all calculated guideline referral rates, our conclusions from the comparison between guidelines are not affected. We conducted a complete case analysis. Billing data was only available for subjects with statutory health insurance and for subjects who gave consent to use their claims data (Fig. 1). Nevertheless, study results are based on 1927 study participants. GFR progression was not available on a yearly basis. Therefore, we used the 5-year progression of $>5 \mathrm{ml} / \mathrm{min}$ or $\geq 15 \mathrm{ml} / \mathrm{min}$ or $\geq 25 \%$ corresponding to the guideline criteria. Our simulation does not allow to assess over- or underutilization of nephrology services or harm to the participants due to the different referral criteria. We have no long-time follow up data regarding renal outcome.

\section{Conclusions}

Applying different proposed referral criteria for CKD patients to specialist nephrology services results in differences in referral rates and costs. Referral rates exceed actually observed consultation rates. Referral criteria need to be evaluated in terms of available workforce and resources but also regarding over- and underutilization of nephrology services.

\section{Declarations}

\section{Ethics approval and consent to participate}

The ethical review board of the University Medicine Greifswald approved the use of SHIP-data and the claims data. Written informed consent was obtained by all study participants. Only data from participants with informed consent were analysed. Data are stored according to the data safety and management plan of the Institute for Community Medicine. The study protocol was

Page $11 / 15$ 
consistent with the principles of the Declaration of Helsinki and approved by the Ethics Committee of the University Medicine of Greifswald.

\section{Consent for publication}

Not applicable

\section{Availability of data and material}

Billing Data cannot be shared publicly due to legal restrictions regarding claims data according to SGB XI. SHIP data are available on reasonable request according the bylaws of the research association of the community medicine https://www.fvcm.med.unigreifswald.de/dd_service/data_use_intro.php.

\section{Conflict of interests}

G. Weckmann, S. Stracke and J.-F. Chenot are authors of the DEGAM guideline Management of patients with chronic non-dialysis kidney disease in general practice. All other authors do not have any conflict of interests.

\section{Funding}

This study was conducted as part of the Renal Function in Ambulatory CarE (REFACE) study, which was funded by the German foundation "KfH Stiftung Präventivmedizin". The study was registered in the German Registry of Clinical Trials (DRKS) under registration number DRKS00009812.

SHIP is part of the Community Medicine Research Network of the University Medicine Greifswald, which is supported by the German Federal State of Mecklenburg/West-Pomerania.

\section{Authors contribution}

AA and GW conceptualized the analysis. SK and AA analysed the data in conjunction with GW and SS. AA, GW and SK interpreted the data. GW, SK and AA were contributors in writing the manuscript. All authors made substantial contributions to the conception of the work, finalized, provided critical review and approved the final manuscript.

\section{Acknowledgement}

SHIP is part of the Community Medicine Research Network of the University Medicine Greifswald and supported by the German Federal State of Mecklenburg-Vorpommern. We are grateful to the Association of Statutory Health Insurance Physicians Mecklenburg-Vorpommern for the permission to link billing data with data from SHIP and to all participants who gave informed consent for linking the data. The authors wish to thank Carolin Zimak for her support in data analysis.

\section{References}

1. Bikbov B, Purcell CA, Levey AS, Smith M, Abdoli A, Abebe M et al. Global, regional, and national burden of chronic kidney disease, 1990-2017: a systematic analysis for the Global Burden of Disease Study 2017. The Lancet 2020; 395(10225):709-33.

2. Cohen E, Nardi Y, Krause I, Goldberg E, Milo G, Garty M et al. A longitudinal assessment of the natural rate of decline in renal function with age. J Nephrol 2014; 27(6):635-41.

3. Brück K, Stel VS, Gambaro G, Hallan S, Völzke H, Ärnlöv J et al. CKD Prevalence Varies across the European General Population. J Am Soc Nephrol 2016; 27(7):2135-47. Available from: URL: https://kdigo.org/wpcontent/uploads/2017/02/KDIGO_2012_CKD_GL.pdf.

4. KDIGO. KDIGO 2012 Clinical Practice Guideline for the Evaluation and Management of Chronic Kidney Disease. Kidney Int Suppl (2011) 2013; 3(1):8-12. 
5. Gergei I, Klotsche J, Woitas RP, Pieper L, Wittchen H-U, Krämer BK et al. Chronic kidney disease in primary care in Germany. J Public Health 2017; 25(2):223-30.

6. Hoffmann F, Boeschen D, Dörks M, Herget-Rosenthal S, Petersen J, Schmiemann G. Renal Insufficiency and Medication in Nursing Home Residents. A Cross-Sectional Study (IMREN). Dtsch Arztebl Int 2016; 113(6):92-8.

7. Smart NA, Dieberg G, Ladhani M, Titus T. Early referral to specialist nephrology services for preventing the progression to endstage kidney disease. Cochrane Database Syst Rev 2014; (6):CD007333.

8. Weckmann GFC, Stracke S, Haase A, Spallek J, Ludwig F, Angelow A et al. Diagnosis and management of non-dialysis chronic kidney disease in ambulatory care: a systematic review of clinical practice guidelines. BMC Nephrol 2018; 19 (1):258.

9. NICE National Institute for Health and Care Excellence. Chronic kidney disease in adults: assessment and management: Clinical guideline; 2014 [cited 2021 Aug 9; Please note: This guidance has been updated and replaced by NICE guideline NG203.].

10. Weckmann G., Chenot J.-F., Stracke S. Versorgung von Patienten mit chronischer nicht-dialysepflichtiger Nierenerkrankung in der Hausarztpraxis [Management of patients with chronic non-dialysis kidney disease in general practice]: S3-Leitlinie [S3guideline]; 2019 [cited 2021 Aug 9]. Available from: URL: https://www.awmf.org/leitlinien/detail/II/053-048.html.

11. Deutsche Gesellschaft für Nephrologie. Praxisratgeber Nephrologie; 2015 [cited 2021 Aug 9]. Available from: URL: https://www.dgfn.eu/praxisratgeber.html.

12. NICE National Institute for Health and Care Excellence. Chronic kidney disease: assessment and management: NICE guideline; 2021. Available from: URL: https://www.nice.org.uk/guidance/ng203/resources/chronic-kidney-diseaseassessment-and-management-pdf-66143713055173.

13. Tangri N, Major RW. Risk-Based Triage for Nephrology Referrals: The Time is Now. Kidney Int Rep 2021; 6(8):2028-30.

14. Gandjour A, Armsen W, Wehmeyer W, Multmeier J, Tschulena U. Costs of patients with chronic kidney disease in Germany. PLoS One 2020; 15(4):e0231375.

15. Völzke H, Alte D, Schmidt CO, Radke D, Lorbeer R, Friedrich N et al. Cohort profile: the study of health in Pomerania. Int J Epidemiol 2011; 40(2):294-307.

16. Levey AS, Stevens LA, Schmid CH, Zhang Y, Castro AF, Feldman HI et al. A New Equation to Estimate Glomerular Filtration Rate. Ann Intern Med 2009; 150(9):604-12.

17. Bevölkerungsstand - Bevölkerung nach Alter und Geschlecht in Mecklenburg-Vorpommern: Teil 1 - Kreisergebnisse 2017; 2018 [cited 2020 May 8]. Available from: URL: https://www.laiv-

mv.de/static/LAIV/Statistik/Dateien/Publikationen/A\%201\%20Bev\%C3\%B6lkerungsstand/A133K/A133K\%202017\%2000.pdf.

18. Delanaye P, Jager KJ, Bökenkamp A, Christensson A, Dubourg L, Eriksen BO et al. CKD: A Call for an Age-Adapted Definition. J Am Soc Nephrol 2019; 30(10):1785-805.

19. Girndt M, Trocchi P, Scheidt-Nave C, Markau S, Stang A. The Prevalence of Renal Failure. Results from the German Health Interview and Examination Survey for Adults, 2008-2011 (DEGS1). Dtsch Arztebl Int 2016; 113(6):85-91.

20. Schwenger V, Hofmann A, Khalifeh N, Meyer T, Zeier M, Hörl WH et al. Urämische Patienten-späte Uberweisung, früher Tod [Uremic patients: late referral - early death]. Dtsch Med Wochenschr 2003; 128(22):1216-20.

21. Raffray M, Vigneau C, Couchoud C, Bayat S. Predialysis Care Trajectories of Patients With ESKD Starting Dialysis in Emergency in France. Kidney Int Rep 2021; 6(1):156-67.

22. Arulkumaran N, Navaratnarajah A, Pillay C, Brown W, Duncan N, McLean A et al. Causes and risk factors for acute dialysis initiation among patients with end-stage kidney disease-a large retrospective observational cohort study. Clin Kidney J 2019; 12(4):550-8.

23. Black C, Sharma P, Scotland G, McCullough K, McGurn D, Robertson L et al. Early referral strategies for management of people with markers of renal disease: a systematic review of the evidence of clinical effectiveness, cost-effectiveness and economic analysis. Health Technol Assess 2010; 14(21):1-184.

24. Onuigbo MAC. The CKD enigma with misleading statistics and myths about CKD, and conflicting ESRD and death rates in the literature: results of a 2008 U.S. population-based cross-sectional CKD outcomes analysis. Ren Fail 2013; 35(3):338-43. 
25. Singh K, Waikar SS, Samal L. Evaluating the feasibility of the KDIGO CKD referral recommendations. BMC Nephrol 2017; 18(1):223.

26. Liu P, Quinn RR, Cortese G, Mahsin M, James MT, Ronksley PE et al. Nephrology consultation and kidney failure in people with stage 4 chronic kidney disease: a population-based cohort study. J Nephrol 2021; 34(4):1225-34.

27. Haase A, Stracke S, Chenot J-F, Weckmann G. Management der nicht dialysepflichtigen chronischen Niereninsuffizienz aus hausärztlicher Sicht - eine qualitative Studie. Dtsch Med Wochenschr 2021.

28. Tangri N, Grams ME, Levey AS, Coresh J, Appel LJ, Astor BC et al. Multinational Assessment of Accuracy of Equations for Predicting Risk of Kidney Failure: A Meta-analysis. JAMA 2016; 315(2):164-74.

29. Bhachu HK, Cockwell P, Subramanian A, Adderley NJ, Gokhale K, Fenton A et al. Impact of Using Risk-Based Stratification on Referral of Patients With Chronic Kidney Disease From Primary Care to Specialist Care in the United Kingdom. Kidney Int Rep 2021; 6(8):2189-99.

30. Tangri N, Stevens LA, Griffith J, Tighiouart H, Djurdjev O, Naimark D et al. A predictive model for progression of chronic kidney disease to kidney failure. JAMA 2011; 305(15):1553-9.

31. Major RW, Shepherd D, Medcalf JF, Xu G, Gray LJ, Brunskill NJ. The Kidney Failure Risk Equation for prediction of end stage renal disease in UK primary care: An external validation and clinical impact projection cohort study. PLoS Med 2019; 16(11):e1002955.

32. Morris JE, Roderick PJ, Harris S, Yao G, Crowe S, Phillips D et al. Treatment burden for patients with multimorbidity: crosssectional study with exploration of a single-item measure. Br J Gen Pract 2021; 71(706):e381-e390.

33. Ware JE, Richardson MM, Meyer KB, Gandek B. Improving CKD-Specific Patient-Reported Measures of Health-Related Quality of Life. J Am Soc Nephrol 2019; 30(4):664-77.

\section{Figures}

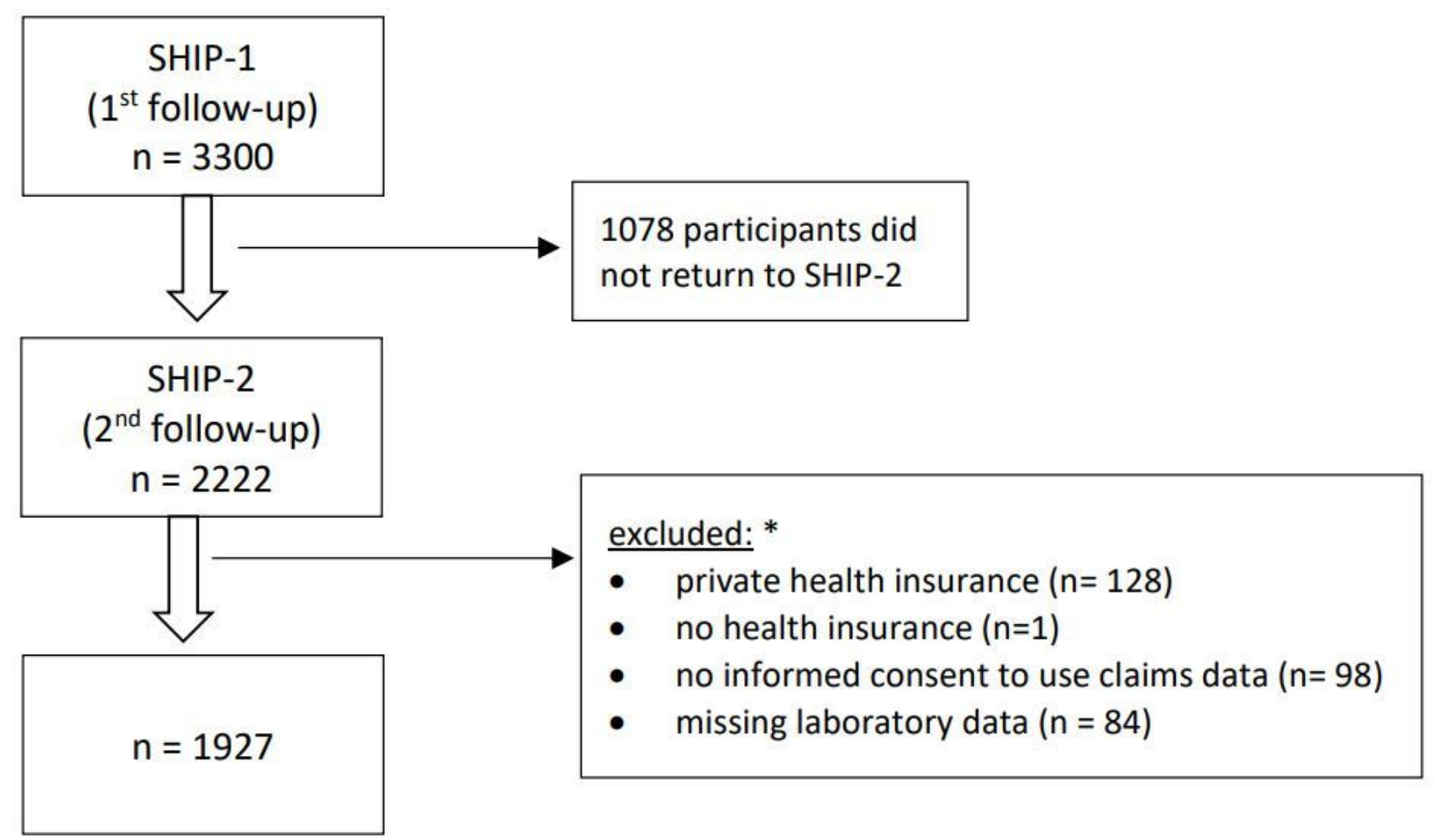

Figure 1 

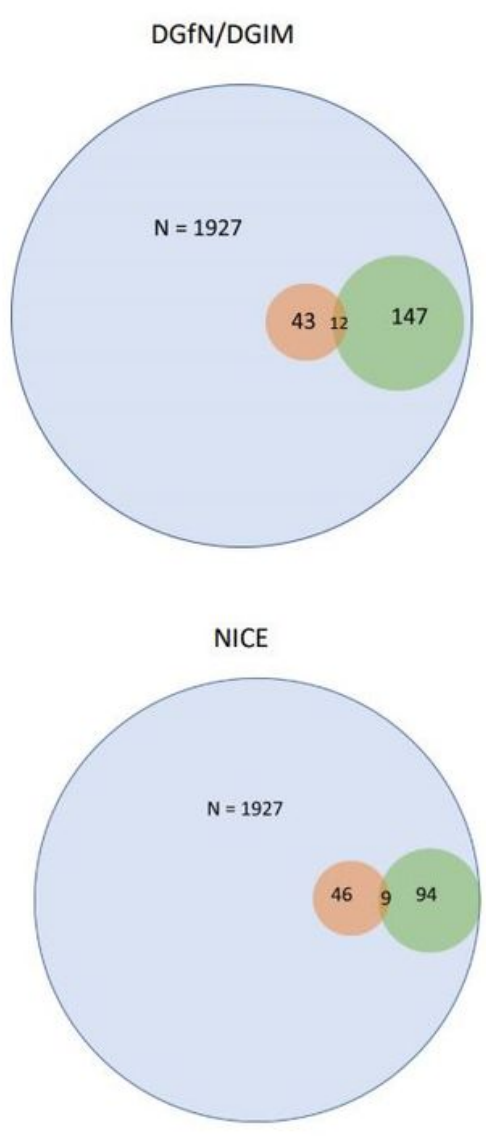

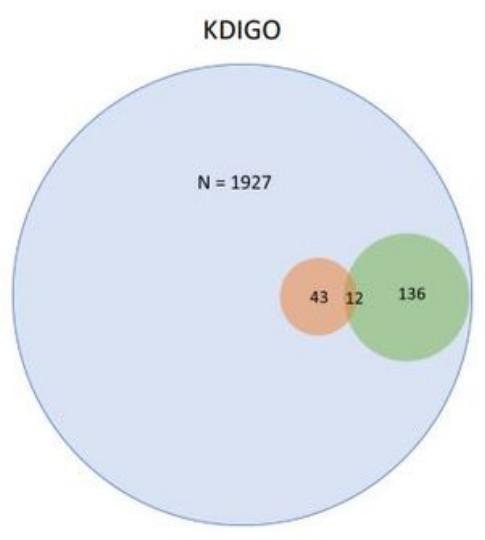

DEGAM

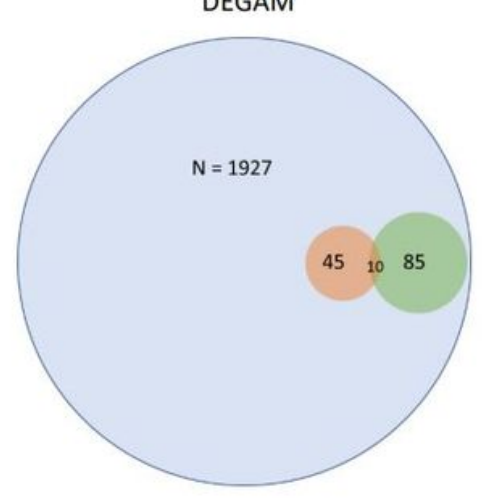

Total number of participants included in study analysis, $\mathrm{N}=1927$

number of participants who actually consulted a nephrologist

number of participants for whom nephrology referral was indicated according to the guidelines/recommendations

\section{Figure 2}

Diagram showing participants referred to a nephrologist according to guidelines/recommendations and participants actually consulting a nephrologist within 1 year prior to study examination (SHIP-2) DGfN/DGIM: German Society of Nephrology/German Society of Internal Medicine; KDIGO: Kidney Disease Improving Global Outcomes; NICE: National Institute for Health and Care Excellence; DEGAM: German Society of General Practitioners and Family Physicians

\section{Supplementary Files}

This is a list of supplementary files associated with this preprint. Click to download.

- Supplements.docx 